\title{
Scinderin, an actin severing and nucleating protein: molecular structure and possible roles in cell secretion, maturation, differentiation and cancer
}

\author{
José-María Trifaró \\ Emeritus Professor, Department of Cellular and Molecular Medicine, School of Medicine, University of Ottawa, Ottawa, Ontario, Canada. \\ Email: Jose-Maria.Trifaro@canada.ca
}

\begin{abstract}
Scinderin is a filamentous actin-severing and capping protein. Segmental deletion and point-mutation studies have shown that this scinderin actin-severing activity resides in its $\mathrm{NH} 2$ terminal half, precisely in domains 1 and 2 . The actin nucleating activity of scinderin is in its domain 5 . Scinderin's F-actin severing activity plays a role in cell secretion. In secretory cells, scinderin is highly concentrated in the cell cortex, showing a distribution similar to that of filamentous actin. Two PIP2-binding sites have been described in scinderin domains 1 and 2. PIP2 inhibits the actin-severing
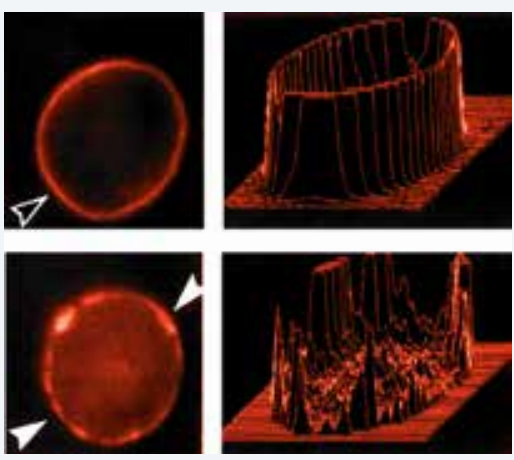
activity of the protein. Several approaches [recombinant scinderin, antisence oligonucleotide, gene promoter activation, vector-mediated expression of scinderin active domains] were used to prove the role of scinderin in secretion. The promoter of $\mathrm{SCIN}$, the scinderin gene, has been characterized and its responsive elements have been described. The activation of the SCIN promoter by two ligands of the aryl hydrocarbon receptor $[\mathrm{AhR}]$ transcription factor has been shown. This activation increased scinderin expression with a resulting increase in stimulation-induced cortical actin disassembly and exocytosis. A role for scinderin in the life cycle of megakaryocytes has also been demonstrated. Scinderin seems to be involved in the maturation, differentiation and apoptosis processes of these cells, releasing newly formed platelets. This completes the life cycle of a megakaryocyte. A role for scinderin in cancer is also emerging. The SCIN gene is silenced in megakaryocyte leukemia cells and its re-expression induces cell maturation, differentiation, apoptosis, as well as the release of platelet-like particles and anti-tumor effects. These are always accompanied by changes in cell morphology due to cytoskeleton re-arrangements. Scinderin over-expression is necessary to see anti-proliferation effects, which are always accompanied by maturation and differentiation. If there were methods to differentiate other types of tumor cells, a new area of treatment would be developed by inducing "cell maturation and/or differentiation".
\end{abstract}

\section{Keywords:}

Scinderin, actin, secretion, megakaryocyte, leukemia

\section{Introduction}

Cells contain actin filaments organized into a variety of structures, including a three-dimensional filament network in the cell cortex under the plasma membrane. This cortical actin network is very predominant in secretory cells [Orci et. al. 1972, Lee and Trifaró 1981, Trifaró 1983]. Actin networks are dynamic structures that go through cycles of filament 
polymerization and de-polymerization as required for cell functions. In secretory cells, cortical actin seems to play a dual role - first, excluding secretory vesicles from releasing sites on the plasma membrane [Vitale et. al. 1991], and second, facilitating secretion through novo filament formation in the latest steps of exocytosis [Trifaró et. al. 2008]. Thus, cell stimulation brings about, in a calcium-dependent manner, a disassembly of the cortical actin filaments allowing the movement of vesicles towards release sites on the plasma membrane.

Cell actin dynamics is controlled through the action of capping and severing proteins. Capping proteins bind to either the pointed end [-] or barbed end [+] of actin filaments and thereby control G-actin unit exchange. Most capping proteins bind to the $[+]$ end, and in this way limit filamentous actin growth. Capping proteins may also have a nucleating capacity under conditions favouring actin polymerization. Among this class of actin capping and severing proteins are fragmin, severin, gelsolin, scinderin and villin [Loppspeich et. al. 1988; Marcu et. al. 1994], which bind to actin in a calciumdependent manner. Work from Trifaró's laboratory [Trifaró et. al. 1985; Bader et. al. 1986] first showed the presence of gelsolin-like proteins in a secretory cell, the chromaffin cell. One of these studies also showed the presence of a $\mathrm{Ca}^{2+}-$ dependent actin-binding protein that was immunologically different from gelsolin [Trifaró et. al. 1985]. The isolation and characterization of this protein was carried in our laboratory [Trifaró et. al. 1989; Rodríguez del Castillo et. al. 1990]. This work has shown that this protein was distinct from gelsolin, although gelsolin was also present in the cell [Bader $e t$ al. 1986; Trifaró et. al. 1989; Rodríguez Del Castillo et. al. 1990]. The name 'scinderin'was given to this protein [a name derived from the Latin "scindere' meaning: 'to cut'], because of its actin filament severing properties [Trifaró et.al. 1989; Rodríguez Del Castillo et. al. 1990]. Subsequent work from our laboratory, demonstrated the presence of scinderin in platelets [Rodríguez Del Castillo et. al. 1992] as well as in other secretory tissues [Tchakarov 1990]. Cloning of scinderin cDNA [Accession number X78479, EMBL Data Library] and sequence analysis done in our laboratory [Marcu et. al. 1994] demonstrated that, similar to gelsolin, another actin severing protein, scinderin has 6 domains with 3 actin-binding sites [Marcu et. al. 1994; 1996; Zhang et. al. 1996].

This review describes the molecular structure and function of scinderin and its possible roles in the secretory process, cell maturation, differentiation and pathological conditions.

\section{Molecular structure and function of scinderin}

Scinderin is a protein with 715 amino acids that shares $63 \%$ and 53\% homology, respectively, with gelsolin and villin [Marcu et al 1994], two other actin-capping and severing proteins [Lottspeich et. al. 1988, Marcu et. al. 1994]. Comparing the scinderin sequence with those of gelsolin and villin reveals that they share six internal short sequence motifs that are repeated [A, B. C; Figure 1]. Two other actin filament severing proteins, severin from the Distyostelium discoideum [Lottspeich et. al. 1988] and fragmin from Physarum polycecephalum [Ampe et. al. 1987], with half the molecular mass of scinderin, also have similarities with the end N-terminal half of scinderin. After aligning motifs A, B and C, gelsolin, villin and scinderin reveal six domains [D1-D6]. There are strong similarities between domains 1 and 4, 2 and 5, and 3 and 6 in gelsolin, villin and scinderin [Marcu et al 1994]. These, added to the fact that fragmin and severin have a better homology with the N-terminal half of scinderin, gelsolin and villin, would suggest that these three proteins have derived by gene duplication from an ancestral actin-filament severing protein which was similar to the N-terminal half of these molecules [Marcu et al 1994]. It has also been suggested that this family of actin filament-severing proteins may have evolved by tandem gene triplication with a predicted $14 \mathrm{kDa}$ monomer unit of 120-130 amino acid residues [Way et. al. 1988]. This is approximately the size of domain or segment 1 in gelsolin.

Previous work from our laboratory has demonstrated that two actin molecules bind one scinderin molecule, and that this interaction is $\mathrm{Ca}^{2+}$-dependent [Trifaró et. al. 1992]. Moreover, the two main fragments (40 and $\left.38 \mathrm{kDa}\right)$ obtained through limited proteolytic digestion interact with actin, also in a $\mathrm{Ca}^{2+}$-dependent manner, yielding actin-fragment complexes of molar ratios 1:1 [Trifaró et. al. 1992]. These results suggest that each scinderin fragment contains an actin- and a $\mathrm{Ca}^{2+}-$ binding site. These results are in agreement with equilibrium dialysis studies [Rodríguez Del Castillo et. al. 1990] that

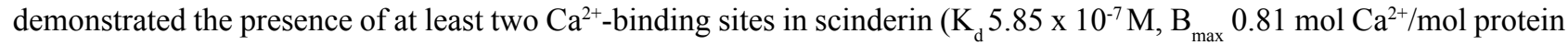
and $\mathrm{K}_{\mathrm{d}} 2.85 \times 10^{-6} \mathrm{M}, \mathrm{B}_{\max } 1.87 \mathrm{~mol} \mathrm{Ca}{ }^{2+} / \mathrm{mol}$ protein). These two $\mathrm{Ca}^{2+}$ sites regulate activation with respect to severin in a single rate-limiting step [Lueck et. al. 2000]. The N-terminal half of scinderin [S1-S3] severs F-actin and sequesters $\mathrm{G}$-actin in a $\mathrm{Ca}^{2+}$-dependent process. In contrast, the N-terminal half of gelsolin (G1-G3) severs and sequesters actin in the absence of $\mathrm{Ca}^{2+}$. Further comparison of scinderin sequences to those of gelsolin and villin showed the presence of two actin-binding site sequences in domains 1 and 2, respectively [Figures 1 and 2]. 


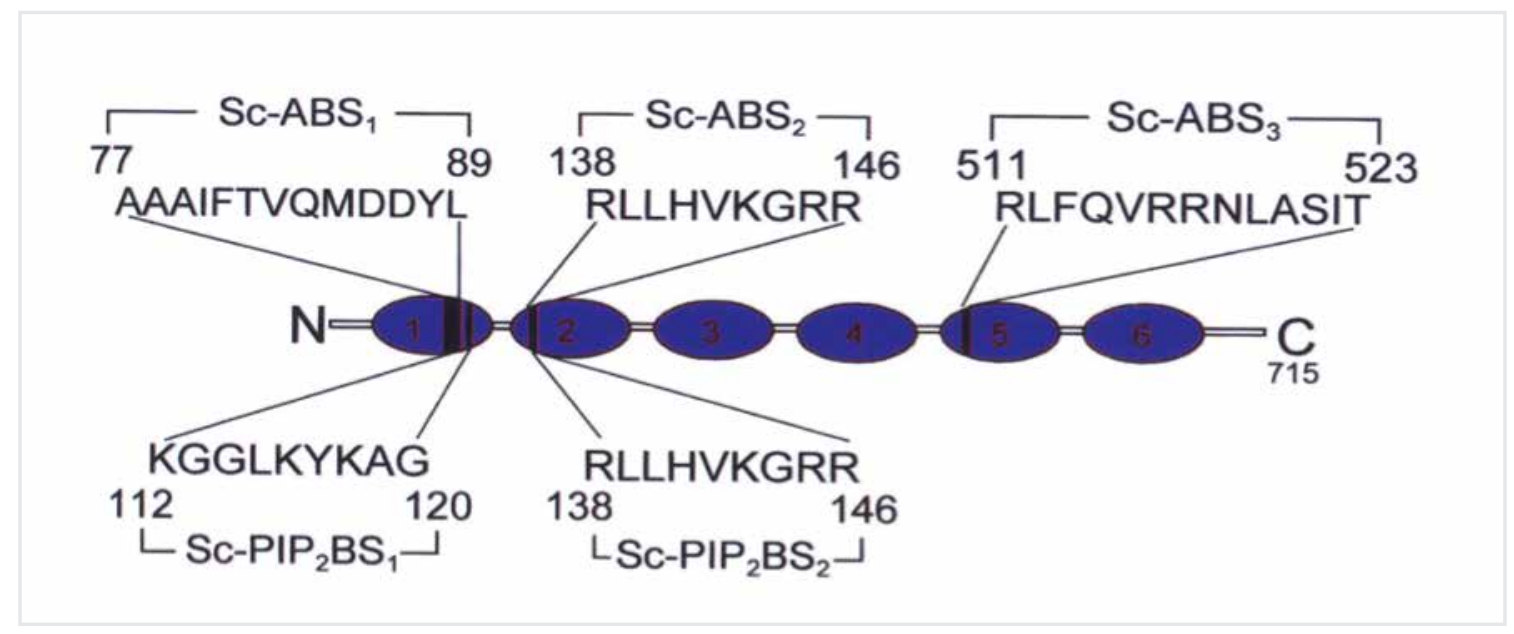

Figure 1. Diagram showing scinderin domains [S1-S6] and scinderin's three actin $\left[\mathrm{ScABS}_{1,2}\right.$ and 3 ] and two PIP ${ }_{2}$ $\left[\mathrm{ScPIP}_{2} \mathrm{BS}_{1 \text { and } 2}\right]$. The amino acid sequence and the number of the first and last amino acid in every construct is indicated. Every domain [S1 to S6] has 3 short sequence motifs - A, B and C - in common with gelsolin and villin, two other F-actin severing proteins.

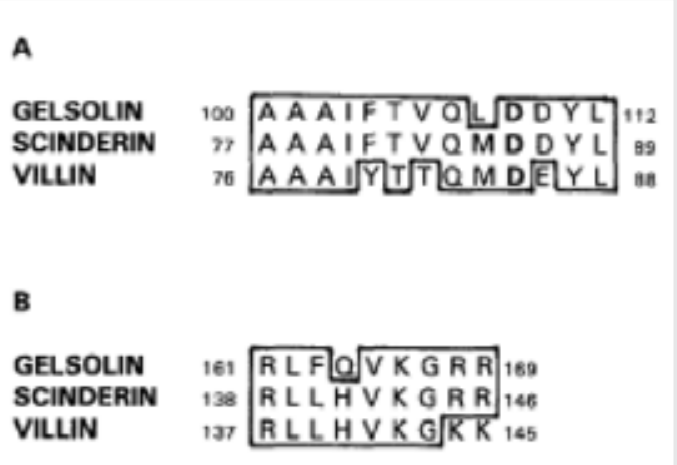

Figure 2. Comparison of amino acid sequences in two Scinderin regions with those sequences in known actin-binding domains of Gelsolin and Villin. Two stretches of amino acid sequences of scinderin from position 77-89 and from 138146 show a high degree of homology with two (A and B) actin-binding domains previously described for human plasma gelsolin and chicken intestinal brush border villin. Aspartate 86 of scinderin corresponds to similar residues in position 109 and 85 of gelsolin and villin, respectively. Aspartate 109 has been shown to be one of $\mathrm{Ca}^{2+}$-binding sites in gelsolin [McLaughlin et. al. 1993]. The numbers on either site indicate the position of amino acid residues.

The high homology between these two actin-binding sites in these proteins would suggest that the type of interaction described between gelsolin domains 1 and 2 and actin regarding the mechanism of filament severing [McLaughlin et. al. 1993] might be similar for scinderin and villin. Moreover, isoleucine residue 103 in gelsolin's first actin-binding site seems to be important for the interaction with subdomains 1 and 3 of actin [McLaughlin et. al. 1993]. Scinderin and villin have an isoleucine in the same position [residues 80 and 79 respectively; Figure $2 \mathrm{~A}$ ] within their actin-binding site [Marcu et. al. 1994]. Comparison of the amino acid sequence of the first actin binding site in these proteins reveals that D86 in scinderin corresponds to D109 and D85 in gelsolin and villin, respectively [Figure 2A]. It has been suggested that one $\mathrm{Ca}^{2+}$ ion is intermolecularly bound between D109 in gelsolin and E167 in actin, with the rest of the coordination links coming from domain G1 in gelsolin [McLaughlin et. al. 1993]. 
A third actin-binding site for actin has also been described in domain S5 in scinderin [Marcu et. al. 1998]. This actin-binding site at the N-terminal of domain $\mathrm{S} 5\left[\mathrm{Sc}^{511-518}\right]$ can bind and nucleate actin assembly. Moreover, $\mathrm{ScABP}_{3}$ a peptide constructed with the sequence (RLFQVRRNLASIT), identical to $\mathrm{Sc}^{511-523}$, blocked the binding of recombinant Sc5-6 to actin and its nucleating activity [Marcu et. al . 1998]. In addition, recombinant Sc5-6 and Sc-ABP 3 also prevent the actin-severing activity of full-length scinderin. This suggests that scinderin, in addition to binding actin on sites present in domains S1 and S2, must bind actin on a third site in domain S5 to sever and nucleate actin effectively [Marcu et. al. 1998]. The crystal structure of the C-terminus in scinderin has been published [Chumnarnsilpa et. al. 2009]. A comparative analysis [Chumnarnsilpa et. al. 2009] of x-ray data from actin-binding surfaces observed in domains G4G6 in gelsolin suggested that scinderin in a similar conformation will also be able to interact with actin through Sc4 and Sc6, and that no interaction should occur with Sc5 as predicted and shown by Marcu et. al. [1998]. The suggestion on the absence of a binding- and nucleating-site for actin in Sc5 [Chumnarnsilpa et. al. 2009] is difficult to accept in view of the extensive published evidence on the location and function of this third actin-binding site of scinderin. The theory of the presence of an actin-binding site in Sc-5 came from experiments on actin nucleation, viscosity of actin gels, serotonin and catecholamine, and grow hormone release during over-expression in secretory cells of fragments Sc5, ScABP3 and ScL5-6 or ScL5; these last two fragments lacking the third actin binding site of scinderin [Marcu et. al. 1998; Trifaró et. al. 2000; Dumitrescu et. al. 2005].

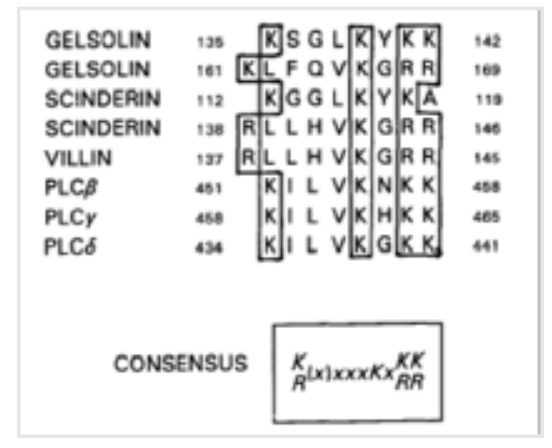

Figure 3. Comparison of amino acid sequences of two scinderin regions with those known PIP ${ }_{2}$ binding sequences. Two stretches of amino acid sequences in scinderin show a high level of homology with villin's PIP ${ }_{2}$ binding site, gelsolin's $\mathrm{PIP}_{2}$ binding sites in domains 1 and 2 [Yu et. al. 1992], and the PIP binding sequence in the conserved ' $\mathrm{X}$ box' of rat phospholipase $C$ family [Rhee et. at. 1989]. The second scinderin sequence (138-145) is identical to villin sequence from position 134-145. The numbers on either side indicate the position of the amino acid residues.

Published work indicates that PIP 2 modulates the activity of many actin-regulatory proteins [Janmey et. al. 1987, Maekawa et. at. 1990, Isenberg 1991], including scinderin [Rodríguez Del Castillo et. al. 1992]. F-Sc1, a fusion protein obtained by the expression of scinderin's domain Sc1 in prokaryotes, binds PS and $\mathrm{PIP}_{2}$ in a $\mathrm{Ca}^{2+}$-dependent manner [Marcu et. al. 1994]. Previous work also carried out by our laboratory has demonstrated that native scinderin has the ability to interact with these two phospholipids [Del Castillo et. al. 1992]. Comparison of amino acid sequences showed the presence in scinderin of sequences that are highly homologous to those known to bind PIP ${ }_{2}$ in gelsolin [Figure 3]. These amino acid sequences are in both scinderin and gelsolin, in the C-terminal of the S1/G1 domain, and in the N-terminal of the S2/G2 domain [Fig 2]. As shown in Figure 3, villin has only one PIP binding site. Interestingly, this sequence is also found in several phospholipase C isozymes [Rhee et. al. 1989, Yu et. al, 1992] where it is known as the 'X Box' [Rhee et. al. 1989]. Scinderin shows a difference in the consensus sequence in one of PIP ${ }_{2}$ binding motifs - there is an alanine instead of a lysine in position 119 [Figure 3]. Consequently, it appears that the replacement of the KK motif by a KA one would impair the ability of scinderin to interact with PIP ${ }_{2}$. However, published evidence on site-directed mutagenesis of gelsolin has shown that a gelsolin mutant with a single lysine $[\mathrm{K}]$ in the ' $\mathrm{X}$ Box' substituted by alanine [A] does not show any decrease in either PIP $_{2}$ binding or its ability to modulate the severing activity [Yu et. al. 1992]. As with gelsolin, the second $\mathrm{PIP}_{2}$-binding site of scinderin overlaps with the second actin-binding site. This would explain, at least in part, the inhibitory effect of $\mathrm{PIP}_{2}$ on gelsolin and scinderin F-actin severing activities [Zhang et. al. 1996]. The binding of PS to scinderin S1 domain [Rodríguez Del Castillo et. al. 1992; Marcu et. al. 1994] is a property not described for gelsolin [Janmey et. al. 1987]. The amino acid sequence responsible for the binding of PS is still unknown. However, 
we have proposed earlier that plasma membrane PS might provide a binding site for scinderin on the inner surface of the membrane [Rodríguez Del Castillo et. al. 1992]. This hypothesis is based on the following facts: a) that scinderin binding to PS liposomes in the presence of other cytosolic proteins is higher at $\mathrm{pH} 6$ and $10^{-8} \mathrm{M} \mathrm{Ca}^{2+}$, a condition similar to that found in resting cells [Rodríguez Del Castillo et. al. 1992; Marcu et al 1994] and b) under resting conditions in secretory cells (i.e. chromaffin cell), scinderin cortical cell distribution does not depend on its binding to actin [ Vitale et. al. 1991; Marcu et. al. 1994].

SCIN, the scinderin gene, is located in chromosome 7 [Cytogenic location7p21.3, Accession number AB067492: GenBank; Nagase et. al. 2001]. It has been shown that SCIN is conserved in chimpanzee, Rhesus monkey, dog, cow, mouse, rat, chicken, zebrafish and frog. The SCIN promoter has also been described and characterized in our laboratory [Trifaró et. al. 2008]. The promoter shows the presence of several $\mathrm{Ap}_{2}$ and four dioxin responsive element [DRE] motifs at $-14,-31,-185$ and -217 upstream of the scinderin initiation site ATG. DREs are recognition sites for the transcription factor aryl hydrocarbon receptor [AhR], and its presence in a secretory cell (i.e., chromaffin cell) has been demonstrated [Trifaró et al, 2008]. The activation of scinderin's promoter in vitro by two AhR ligands; 2, 3, 7, 8-tetrachlorodibenzop-dioxin [TCDD], and all trans-retinoic acid [ATRA] with the consequent increase in scinderin transcription and overexpression was also demonstrated. Treatment of chromaffin cell cultures for $48 \mathrm{hr}$. with either $10 \mathrm{nM}$ TCDD or $10 \mu \mathrm{M}$ ATRA resulted in high levels of scinderin expression and potentiation of cell depolarization-induced F-actin disassembly and catecholamine release [Trifaró et. al. 2008].

\section{Scinderin in the secretory process}

The F-actin severing activity of scinderin seems to play a role in cell secretion [Vitale et. al. 1995; Zhang et. al. 1996; Marcu et. al. 1996]. Scinderin is present in secretory cells, including chromaffin cells [Rodríguez del Castillo et. al. 1990] and platelets [Rodríguez Del Castillo et. al. 1992]. In chromaffin cells, scinderin is highly concentrated in the cortex [Vitale et. al. 1991], showing a distribution similar to that of filamentous actin [Vitale et. al. 1991]. Immunocytochemical experiments have shown that cell stimulation simultaneously induces cortical F-actin disassembly and redistribution of subplasmalemmal scinderin [Vitale et. al. 1991]. Stimulation removal allows cells to recover actin and scinderin cortical localization, as demonstrated by immunocytochemistry [Vitale et al 1991]. However, cortical scinderin distribution is recovered before cortical actin distribution, suggesting that scinderin is bound to structures other than cortical actin at the subplasmalemmal zone of the cell [Vitale et. al. 1991], as indicated above. Consequently, cortical F-actin acts as a barrier to the free movement of secretory vesicles to release sites (Figure 4), and only during cell stimulation-induced $\mathrm{Ca}^{2+}$ entry, cortical F-actin is disassembled through a $\mathrm{Ca}^{2+}$ dependent activation of scinderin (Vitale et. al. 1991). This would allow the movement of secretory vesicles (Figure 4) towards release sites on the plasma membrane [Vitale et. al. 1991; Trifaró et. al. 1992, Vitale et. al. 1995]. Areas of actin disassembly correspond to plasma membrane areas of vesicle exocytosis as the experiments with dopamine $\beta$-hydroxylase antibodies have demonstrated [Trifaró et. al. 1993]. Ultrastructural [Tchakarov 1998] and path clamp experiments [Vitale et. al. 1995] have confirmed this hypothesis. Secretory vesicles are in different cellular pools (Reserve pool: Pool A; Readily-releasable: Pool B, Immediately-releasable: Pool C), where vesicles are in various states of release ability. The transit of vesicles between compartments is not random, but an event controlled and regulated by $\mathrm{Ca}^{2+}$, the cortical actin network and their regulatory proteins [Trifaró 1997]. Myosin V seems to be the molecular motor involved in the transport of secretory vesicles from the reserve pool to the release-ready vesicle pool [Rosé et. al. 2003]. 

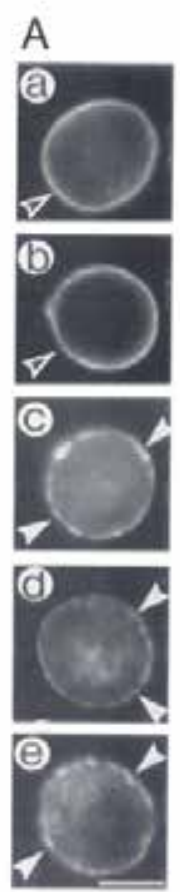

B

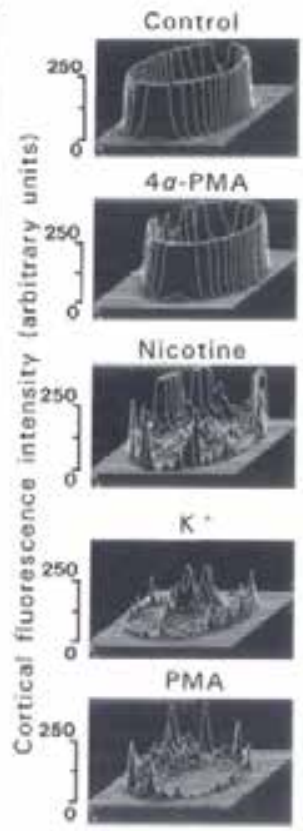

$\mathrm{C}$

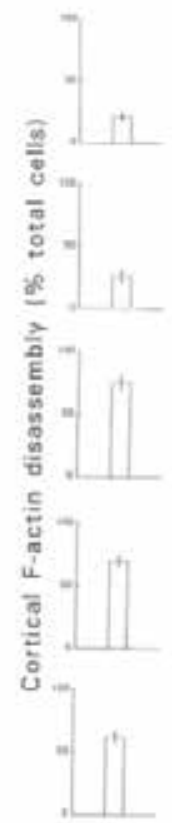

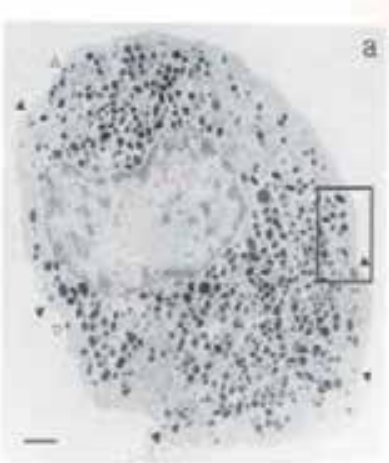

a

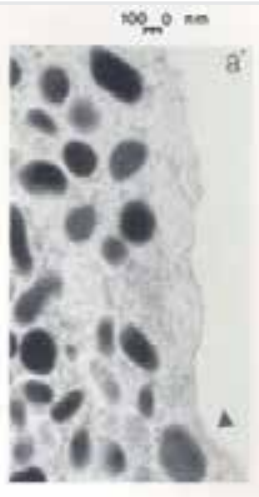

$100.9 \mathrm{~mm}$
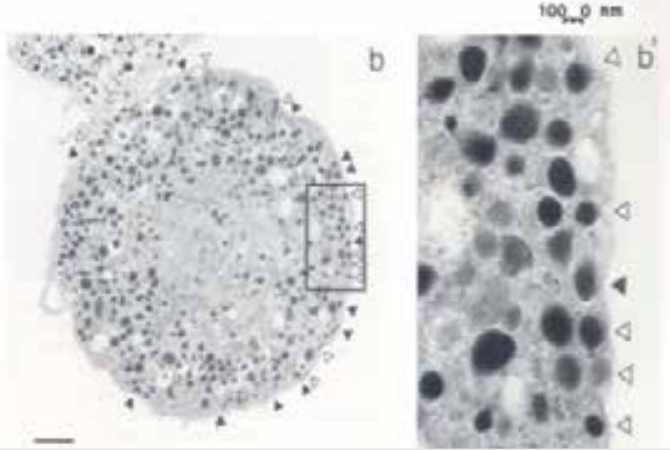

Figure 4. A) Fluorescence microscopy and B) video-enhanced image analysis of F-actin fluorescence profiles (rhodamine-phalloidin staining) in chromaffin cells under controlled or stimulated conditions. (C) shows the effects of different treatments on the percentage of cells displaying cortical F-actin disassembly. Control cells in (A) and (B) show a contiguous and bright fluorescent cortical ring (open arrowheads). $4 \alpha$-PMA is an inactive isomer of PMA. Stimulation with nicotine, high $\mathrm{K}+$ and PMA caused the disruption of the cortical fluorescent ring (actin disassembly). Some fluorescent patches are shown by closed arrowheads. B) Three-dimensional image analysis of cells shown in (A). In stimulated cells [c, d and f], the cortical fluorescence patterns show irregularities such as valleys and peaks. The peaks correspond to the fluorescent patches of cells shown in (A). The four panels on the right show electron micrographs of isolated adrenal chromaffin cells, control in upper panels and stimulated in lower panels. (A) shows a control cell with a cortical zone of $150 \mathrm{~nm}$, practically devoid of secretory vesicles. In this exclusion zone, only few secretory vesicles (about 200 vesicles per cell) are located close $(0-50 \mathrm{~nm})$ to the plasma membrane (closed arrowhead). (A') shows a large magnification of the area within the box in (A). Most secretory vesicles in control cells are situated at about $150 \mathrm{~nm}$ from the plasma membrane and separated from the plasma membrane by cortical F-actin. B) stimulated cells show an increased number of secretory vesicles in the $0-50 \mathrm{~nm}$ area (open arrowheads). These are areas of cortical F-actin disassembly and exocytosis. This can be seen at higher magnification in (B'). Magnification: 234x (A); 10,773x (B); 51,072x (A' and B'). Bar: $1 \mu \mathrm{m}$.

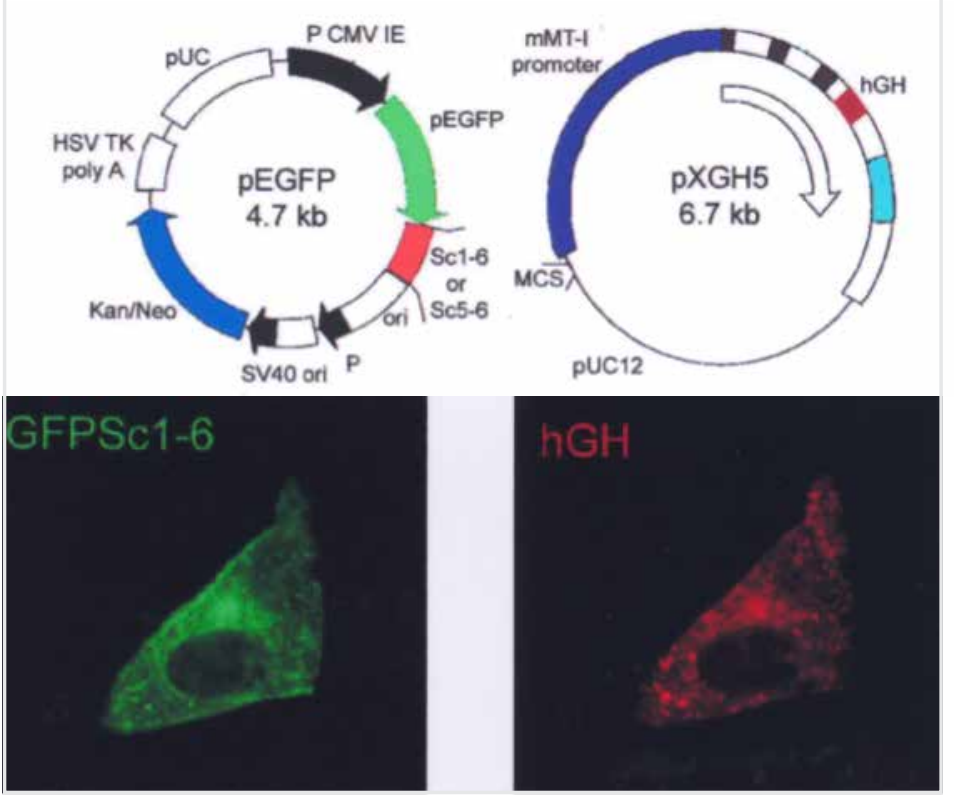

Figure 5. Co-expression of green fluorescent protein [GFP]-fused Scinderin [Sc] and human growth hormone $[\mathrm{hGH}]$ gene in chromaffin cells. A diagram of the components of the two vectors used in co-transfection is shown at the top of the figure. Co-transfected cells were fixed, permeabilized and stained for hGH using a polyclonal antibody against hGH. The immunocytochemistry panel shows a co-transfected cell stained for hGH and, at the same time, expressing GFPSc1-6. In these experiments, co-transfected chromaffin cells synthesized hGH and stored it in chromaffin vesicles (dopamine B-hydrolase positive vesicles). Several Sc constructs [Sc1-2, Sc5-6, Sc5, ScL5, $\mathrm{ScABS}_{2}$ ] were also prepared and co-transfected with the hGH carrying vector. See Figures 6 and 7 and Dumitrescu et. al. [2005]. 
Four approaches followed in our laboratory have demonstrated a role of scinderin in secretion:

1) $\mathrm{Ca}^{2+-i n d u c e d ~ F-a c t i n ~ d i s a s s e m b l y ~ a n d ~ e x o c y t o s i s ~ f r o m ~ p e r m e a b i l i z e d ~ c h r o m a f f i n ~ c e l l s ~ a n d ~ p l a t e l e t s ~ w a s ~ i n c r e a s e d ~}$ by recombinant scinderin [Zhang et. al. 1996; Marcu et. al. 1996]. No effects were observed when recombinant scinderin was devoid of actin-binding sites 1 and 2 (truncated Sc). Recombinant scinderin-evoked increases in exocytosis of catecholamines and serotonin in permeabilized chromaffin cells and platelets, respectively, were inhibited by exogenous G-actin, by two peptides with sequences corresponding to the two scinderin actin-binding sites $\left(\mathrm{ScABS}_{1}\right.$ and $\mathrm{ScABS}$ ), and by $\mathrm{PIP}_{2}$, an inhibitor of scinderin activity [Zhang et. al. 1996; Marcu et. al. 1996]. These results were confirmed in mouse pancreatic $\beta$-cells, where three peptides with sequences corresponding to each of three actin-binding sites of scinderin inhibited insulin stimulated secretion as measured by patch clam [Trine et. al. 2000].

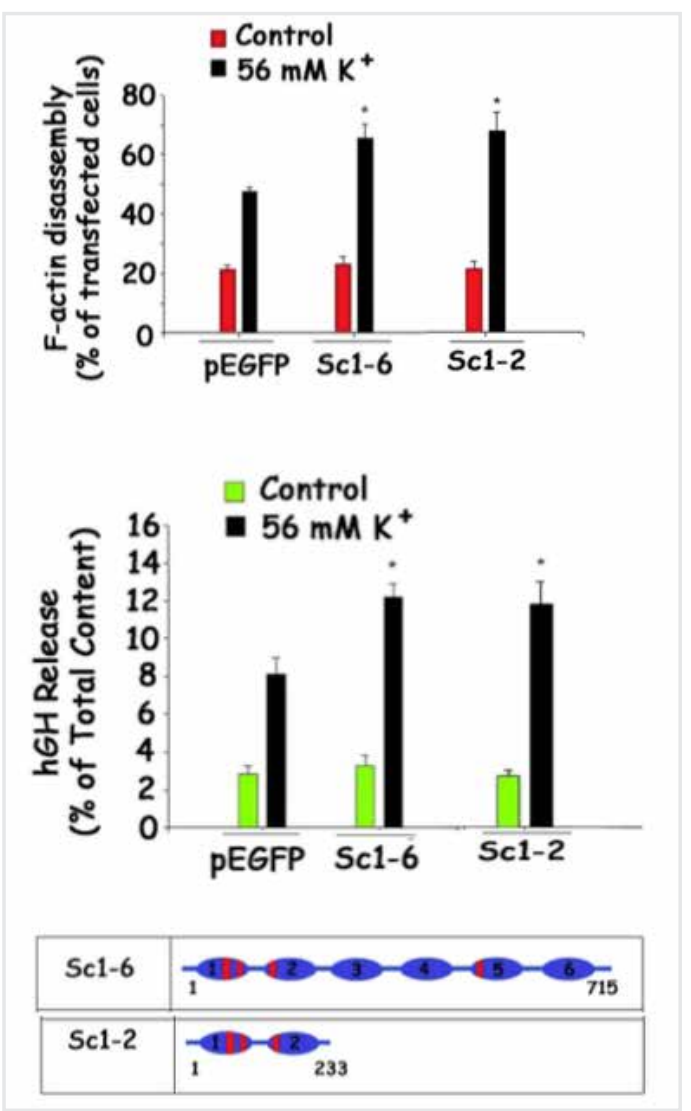

Figure 6. Effects of over-expression of scinderin [S1-6] and a construct [Sc1-2] with F-actin severing activity on cortical F-actin disassembly and human growth hormone $[\mathrm{hGH}]$ release from chromaffin cells upon high $\mathrm{K}^{+}$-induced cell depolarization. A schematic representation of constructs is shown at the bottom of the figure. A potentiation of both cortical actin disassembly and hGH release is observed in cells over-expressing Sc 1-6 and Sc1-2. Control cells were cotransfected with vector [pEGPP] alone [Dumitrescu et. al. 2005].

2) Oligonucleotide targeting the scinderin gene SCIN decreased the expression of scinderin and depolarization and/ or $\mathrm{Ca}^{2+}$-evoked F-actin disassembly and exocytosis, either in intact or permeabilized secretory cells (Figure 8A) [Lejen et. al. 2001].

3) The promoter region of SCIN has, as indicated above, dioxin-responsive element [DRE] sequences and binding sites for the transcription factor aryl hydrocarbon receptor (AhR), a receptor shown to be present in chromaffin cells. Ten nM TCCD (2,3,7,8-tetra-chlorodibenzo-p-dioxin) or $10 \mu \mathrm{M}$ ATRA (all trans-retinoic acid), both ligands for the $\mathrm{AhR}$, increased scinderin expression and potentiated stimulation induced F-actin disassembly and exocytosis (Figure 8B) [Lejen et. al. 2003; Trifaró et. al. 2008]. 
4) Similar potentiation of F-actin disassembly and exocytosis was observed with vector-mediated expression of full length scinderin or its active domains S1-Sc2 (Figure 6) [Dumitrescu et. al. 2005]. On the other hand, vector-mediated expression of scinderin domains S5-6, S5 or $\mathrm{ScABS}_{3}$ (a peptide with the amino acid sequence of actin-binding site 3), all with actin nucleating activity, decreased F-actin disassembly and exocytosis (Figure 7) [Dumitrescu et. al. 2005]. All these effects were probably due to an increase or decrease in the number of chromaffin vesicles at release sites (see also Figure 4). Additional experiments suggest that scinderin acts as a molecular switch during the secretory cycle; thus inducing F-actin disassembly when intracellular $\mathrm{Ca}^{2+}$ increases and, later in the cycle, when $\mathrm{Ca}^{2+}$ has returned to normal levels, promoting actin nucleation (through the third actin-binding site in domain S5) and polymerization with restoration of cortical actin networks [Dumitrescu et. al. 2005].

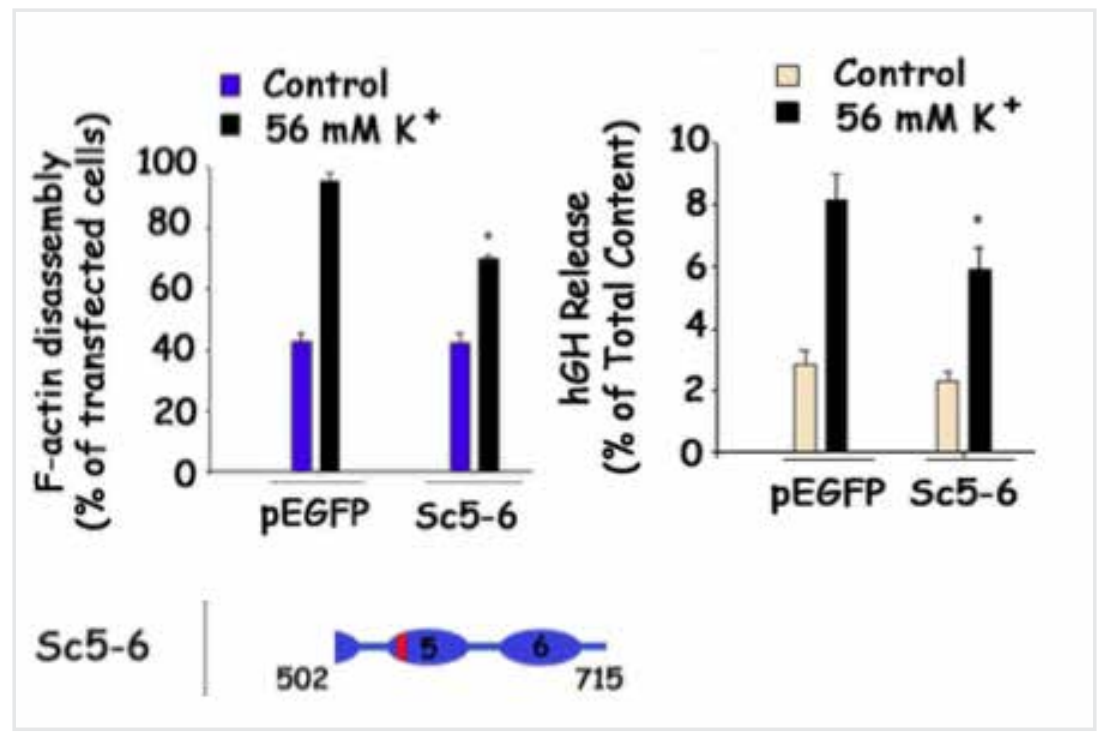

Figure 7. Effects of over-expression a [Sc5-6] construct with actin-nucleating activity on cortical actin and human growth hormone $[\mathrm{hGH}]$ release from chromaffin cells upon high $\mathrm{K}^{+}$-induced cell depolarization. A schematic representation of the $\mathrm{Sc}$ construct is shown at the bottom of the figure. Both cortical actin disassembly and hGH release were significantly decreased in cells co-transfected with Sc5-6. Similar results were obtained with other constructs $\left[\mathrm{Sc} 5, \mathrm{ScABS}_{2}\right]$ with actin-nucleating activity. ScL5, a construct without a scinderin nucleation site, did not show an inhibitory effect on cortical actin disassembly and hGH release [Dumitrescu et. al. 2005].

There is also a second cellular mechanism that controls actin networks in secretory cells involving protein kinase $\mathrm{C}$ activation and induction of a myristoylated alanine-rich $\mathrm{C}$ kinase substrate (MARKS) phosphorylation [Elzagallaai et. al. 2000, 2001, Rosé et. al. 2001]. MARKS cross-links actin filaments and stabilizes actin networks. Its phosphorylation by protein kinase $\mathrm{C}$ activation eliminates the cross-linking of actin filaments with the consequent actin filament disassembly [Rosé et. al. 2001]. Contrary to receptor activation of $\mathrm{Ca}^{2+}$ entry through plasma membrane $\mathrm{Ca}^{2+}$ channels, a requirement for scinderin activation, MARKS-dependent actin filament disassembly is mainly observed when $\mathrm{Ca}^{2+}$ is released from the endoplasmic reticulum [Zhang et. al. 1995, Trifaró et. al. 2000]. This is observed when cells are stimulated by histamine [Zhang et. al. 1995]. 


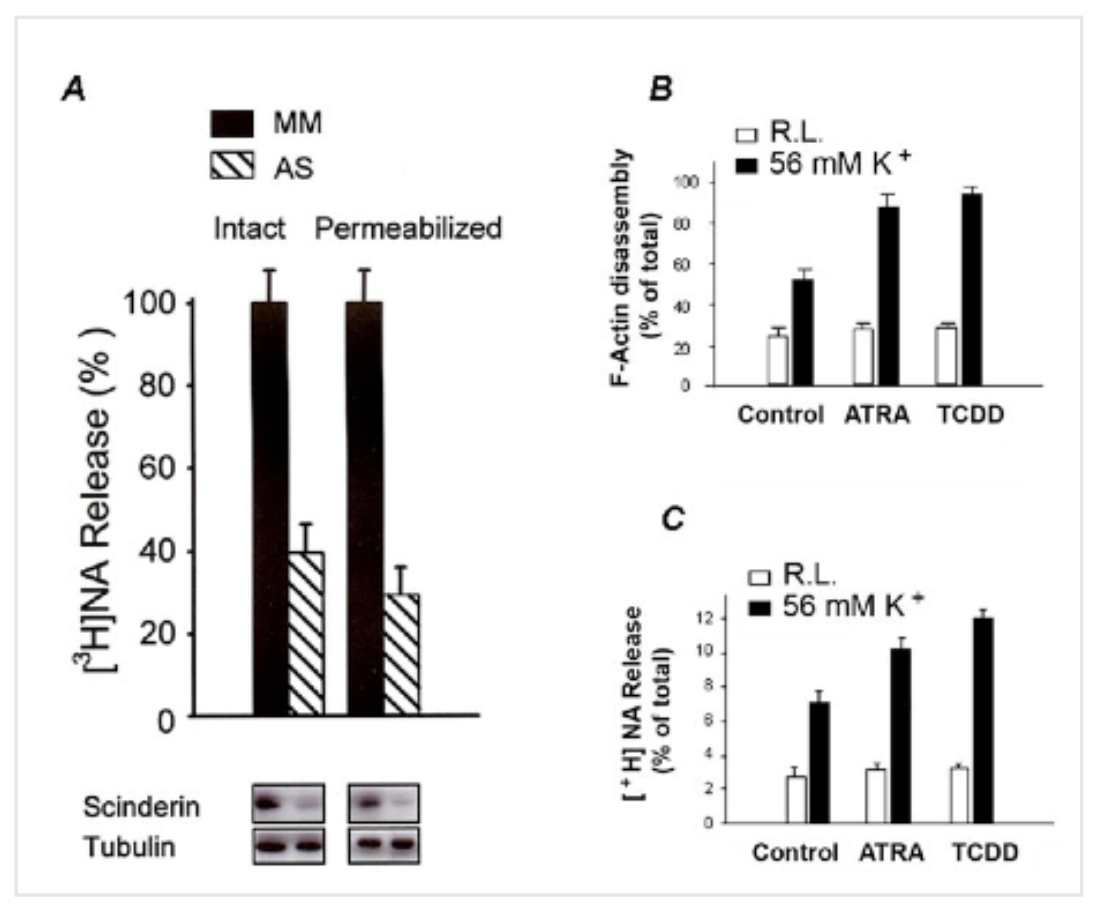

Figure 8. A) Intact or permeabilized chromaffin cells were stimulated for 60 sec. with $56 \mathrm{mM} \mathrm{K}^{+}$or $20: \mathrm{M} \mathrm{Ca}^{2+}$ respectively. Cell cultures were previously incubated for $72 \mathrm{hr}$. with either scinderin antisense oligodeoxynucleotide (AS) or its oligodeoxynucleotide mismatch (MM, control). At the bottom, Western blots of samples from the cultures showing decreased scinderin expression in the AS-treated cells. Similar effects were observed with cortical F-actin disassembly. B) and C) Scinderin gene promoter stimulation: Cell cultures were treated with $10 \mu \mathrm{M}$ ATRA or $10 \mathrm{nM}$ TCCC for $48 \mathrm{hr}$. and then, stimulated by high $\mathrm{K}^{+}$. A potentiation of B) $\mathrm{F}$-actin disassembly and $\left.\mathrm{C}\right)\left[{ }^{3} \mathrm{H}\right]$-noradrenaline output was observed [Trifaró et. al. 2008].

\section{Scinderin in cell maturation and differentiation}

Acute megakaryoblastic leukemia (M7) is a recognized disorder characterized by rapid proliferation of atypical megakaryocytes and their precursor cells. This disease is often associated with myelofibrosis. Cell lines have been established with cells from patients with this disease [Ogura et. al. 1985] and these cells have shown some degree of differentiation with phorbol ester (PMA) treatment. Megakaryopoiesis is a complex process that involves the proliferation of committed precursor cells and their differentiation with nuclear polyploidization, leading to platelet formation [Leven and Yee 1987]. This process is thought to be regulated by a lineage-specific humoral factor called thrombopoietin. After differentiation, the fate of megakaryocytes is apoptosis, with cell fragmentation resulting in cytoplasmic areas released as newly formed platelets [Zauli et. al. 1997].

Cells from patients with this disorder and cell lines established from this type of leukemia showed the presence of gelsolin but the absence of scinderin expression (Figure 9A) [Zunino et. al. 2001]. These two actin filament-severing proteins are present in normal megakaryocytes and platelets [Rodríguez Del Castillo et. al. 1991]. Vector-mediated expression of scinderin in the megakaryoblastic cell line MEG-01 induced a decrease in both F-actin (Figure 9B) and gelsolin. This was accompanied by increased Rac2 expression and by activation of the PAK/MEKK.SEK/JNK/c-jun, $c$-fos transduction pathway [Zunino et al 2001]. An increase in Rac might be the result of the decreased expression of gelsolin observed in these cells, because it has been demonstrated that there is a reciprocal correlation between gelsolin and Rac expressions [Azuma et. al. 1998]. Indeed, in experiments with MEG-01 cells, a good reciprocal correlation between the levels of these 2 proteins was also observed [Zunino et. al. 2001]. In gelsolin-null mice, Rac is overexpressed and the re-expression of gelsolin in these animals restores normal levels of Rac [Azuma et. al. 1998]. The Raf/MEK/ERK pathway was also activated in these cells. There was evidence that an earlier activation of the Raf-MEK-ERK pathway increased expression of platelet antigen CD41a between days 4 and 8 in cell culture. 


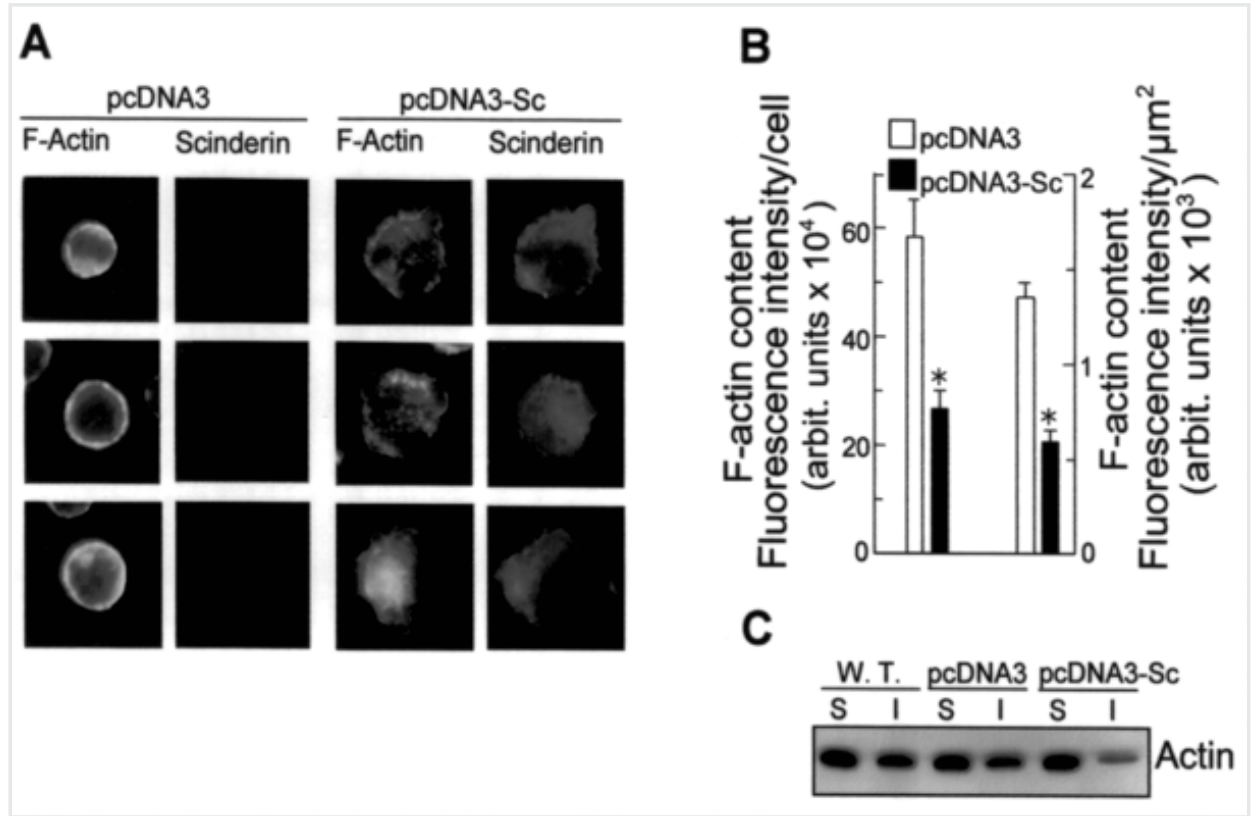

Figure 9. Effect of scinderin expression and filamentous actin content in MEG-01 cells. A) Fluorescence microscope images of cells stained with scinderin (Sc) antibodies and rhodamine phalloidin (a probe for F-actin) after transfection either with vector pcDNA3 (2 left panels) or with Sc cDNA carrying vector pcDNA3-Sc (2 right panels). B) Image analysis data of the fluorescent cells described in panel A. C) Western blot analysis carried out with actin antibody of wild type (WT) cells and transfected cells. S: supernatants and sediments of Triton-100 insoluble extracts (I). Twelve preparations of pcDNA3-transfected cells were analyzed, and 18 preparations from 3 different clones (6 from each clone) were measured for pcDNA3-Sc-transfected cells $(* P<.001)$ [Zunino et. al. 2001].

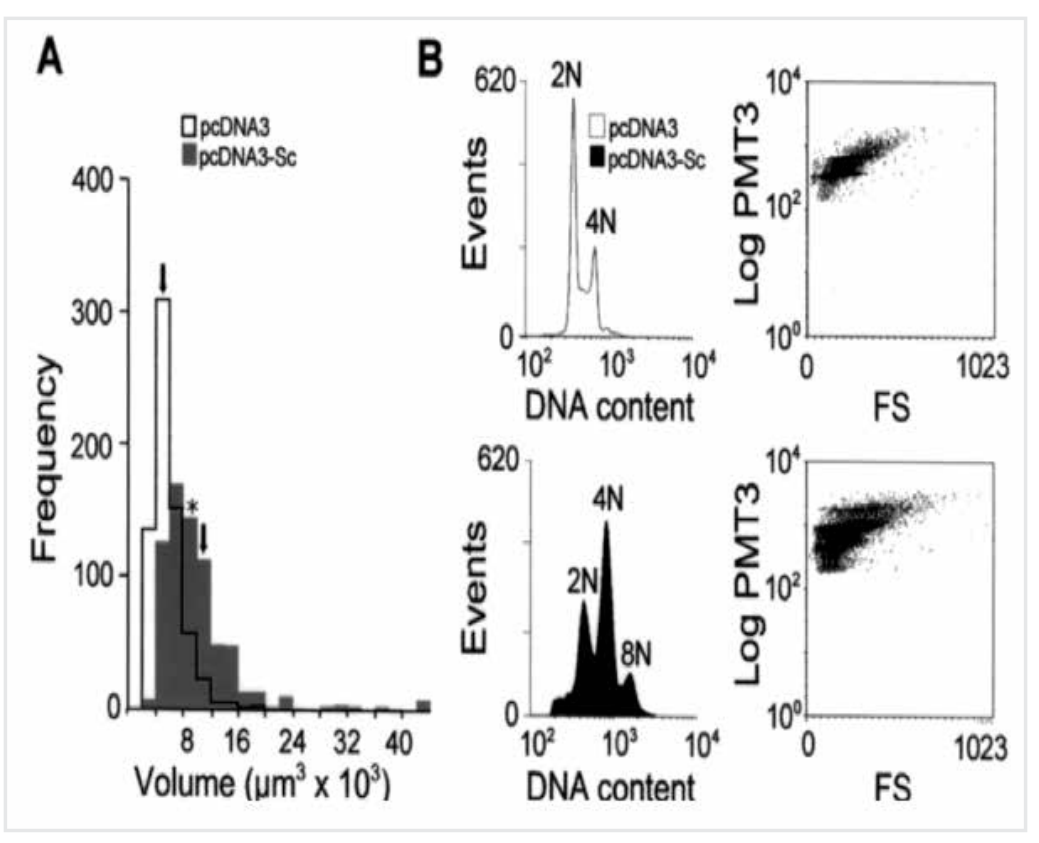

Figure 10. Effect of scinderin expression on MEG-01 volume and nucleus number. Cells transfected with either pcDNA3 or pcDNA3-Sc were cultured for 8 days after removal of the antibiotic G 418. A) and B) Cells were then fixed and stained with Wright-Giemsa, and $(A)$ volumes of pcDNA3 $(n=484)$ and pcDNA3-Sc $(n=600)$ transfected cells were measured $\left({ }^{*} P<.001\right)$. B) Comparison of gated DNA distribution of 35000 cells transfected with pcDNA3 and the same number of cells transfected with pcDNA3-Sc (clone Sc I-E). Similar results were obtained with 5 other Sc expressing clones [Zunino et. al. 2001]. 
Transduction pathway activation was followed by cell volume increase (Figure 10A) differentiation (Figure 11), polyploidization (Figure 10B), maturation (Figure 11), and apoptosis with release of platelet-like particles. Particles expressed surface CD41a antigen (glycoprotein IIb/IIIa or fibrinogen receptor), had dense bodies, high-affinity serotonin transport, and circular array of microtubules [Zunino et. al. 2001]. Treatment of particles with thrombin, and similar to normal platelets, induced serotonin release and aggregation that was blocked by CD41a antibodies. PAC-1 antibodies also blocked aggregation [Zunino et. al. 2001].

Similar to chromaffin cells, and as discussed above, stimulation of the MEG-01 transcription factor AhR by two of its ligands (dioxin and ATRA, see above) induced expression of scinderin, polyploidization and expression of antigen CD41a (Figure 12); all manifestations of maturation and differentiation. Exposure of cells to PD98059, a blocker of MEK, inhibited all: antigen CD41a expression, increases in cell volume, and number of protoplasmic extensions [Zunino et. al. 2001]. Therefore, it seems that the restitution of scinderin expression in human megakaryoblastic leukemia cells activates specific transduction pathways leading to cell differentiation and maturation.
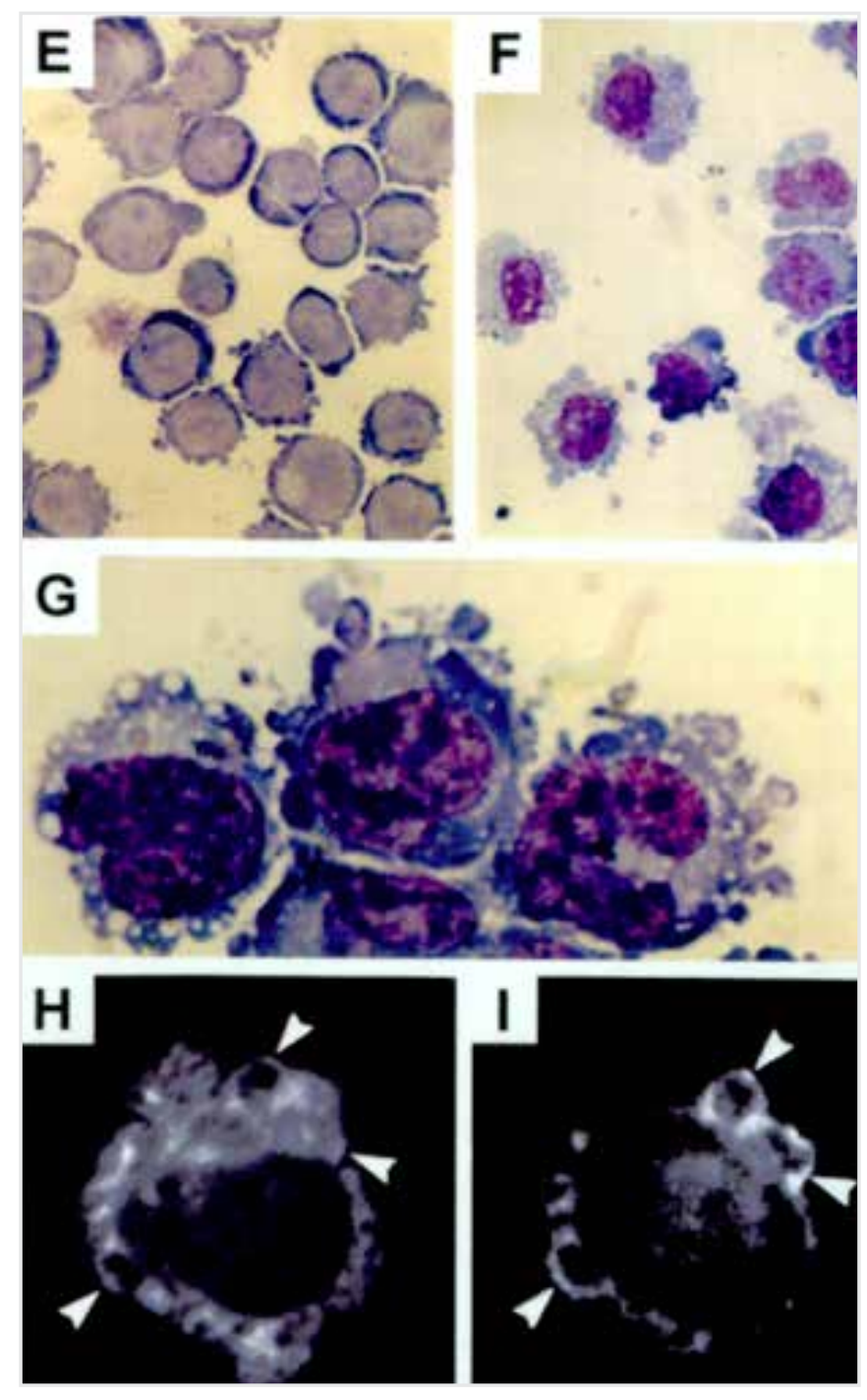

Figure 11. Cells, cultured for 12 days, were also fixed and stained with Wright-Giemsa (E-G) or rhodamine phalloidin, a probe for F-actin (I), or they were immunostained with a Sc antibody $(\mathrm{H})$. Cells transfected with pcDNA3 (E) showed a large single nucleus surrounded by a thin layer of cytoplasm $(\times \mathbf{4 0 0})$. F) Cells expressing Sc (pcDNA3-Sc) were much larger and were multinucleated or had multi-lobulated nuclei, abundant cytoplasm, and numerous cytoplasmic extensions $(\times \mathbf{4 0})$. G) Same cells at a large magnification $(\times \mathbf{1 0 0 0})$. Distribution of Sc $(\mathrm{H})$ and filamentous actin (I) in a doublestained cell $(\times \mathbf{1 2 0 0})$. There was some degree of correlation between the distribution of the 2 markers, especially in the cytoplasmic extensions (arrowheads). 
Furthermore, it has also been demonstrated that scinderin is up-regulated during chondrocyte maturation, and the observed increased expression of Indian hedgehog (Ihh) and collagen type X is indicative of chondrocyte differentiation [Nurminsky et. al. 2007]. As with MEG-01 cells, the MEK-ERK pathway was activated and its inhibition blocked chrondrocyte differentiation [Nurminsky et. al. 2007].

\section{Scinderin in cancer}

As discussed above, the expression of the scinderin gene in MEG-01 cells induces their maturation and differentiation. Moreover, cell proliferation and cell ability to form tumors in nude mice were also inhibited by the expression of scinderin [Zunino et. al. 2001]. An important observation in this study was the fact that cells expressing scinderin either did not form tumors in nude mice or that the small tumors observed in two of nine cases have histologic characteristics different from those large, solid, and vascularized tumors observed in mice injected with cells previously transfected with vectors alone (Figure 13). The two small tumors produced by pcDNA3-Sc-transfected cells showed cells in apoptosis surrounded by large numbers of platelet-like particles, a situation similar to that observed in vitro. Therefore, it seems that the restitution of scinderin expression in human megakaryoblastic leukemia cells activates specific transduction pathways leading not only to cell differentiation and maturation, but also to the inhibition of proliferation and tumor formation (Figure 13). Whether these cells had acquired all characteristics of normal cells, including lack of tumorigenesis, remains to be determined.

\section{MEG-01 CTL}

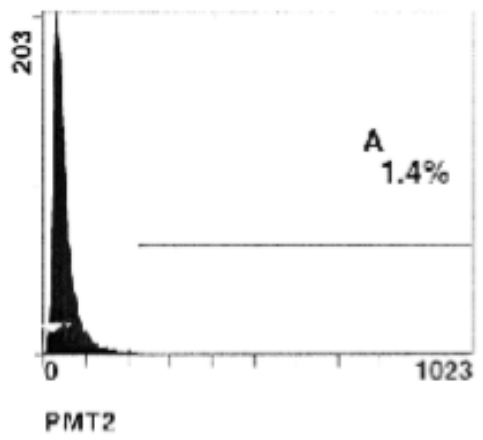

MEG-01, TCDD 21d

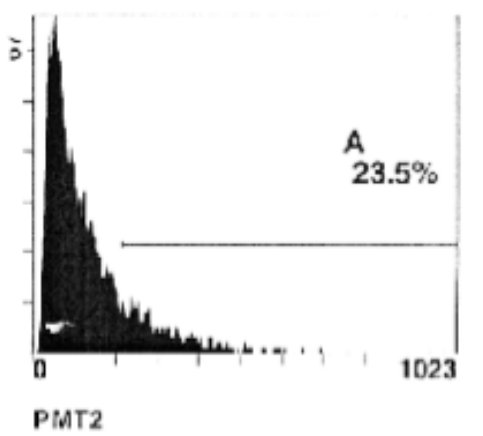

Figure 12. Flow cytometry showing an Increase of CD41a (glycoprotein IIb/IIIa or fibrinogen receptor) expression in MEG-01 cells by stimulation of scinderin promoter with a TCDD 21-day treatment. An Increase expression of 15.4 times was observed. Activation of the Raf/MEK/ERK was involved in this increased CD41a expression [Zunino et. al. 2001].

Scinderin expression was absent from human megakaryoblastic leukemia cells as well as from cell lines derived from these malignant cells [Zunino et. al. 2001]. On the other hand, scinderin is also well expressed in other types of malignant cells [Abouzahr et. al. 2006, Miura et. al. 2012, Hasmim et. al. 2012, Wang et. al. 2014].

In the prostate carcinoma cell line PC3, the knock down of the SCIN gene by a lentivirus-mediated RNAi technique inhibited the proliferation and colony formation ability of these cells. Moreover, a cell cycle analysis showed that decreased SCIN expression lead to GO/G1 cell cycle arrest through the regulation of cell cycle genes, such as p21Waf1/Cip1, cyclindependent kinase inhibitor 2A (CDKN2A, p16ln4A) and cyclin A2 [Wang et. al. 2014]. These results allowed the authors to conclude that SCIN plays an important role in the proliferation of prostate cancer cells and that inhibition of SCIN expression may be a potential therapeutic method in this cancer type.

Similarly, a non-small-cell lung carcinoma cell line rendered resistant to T cell lysis (CTL) showed over-expression of actin-related genes EFNA1 and SCIN. These cells resistant to $\mathrm{CD} 8^{+}$cytolytic $\mathrm{T}$ lymphocytes also displayed strong morphological changes and alterations of the actin cytoskeleton [Abouzahr et. al. 2006]. Silencing of these genes using 
RNA interference resulted in a restoration of normal cell morphology and a significant attenuation of variant resistance to CTL killing. Consequently, a shift in cytoskeletal organization may allow cancer cells to promote their resistance to T cell lysis.

Cisplatin is a most effective antitumor agent available against bladder cancer. It promotes apoptosis of bladder cancer cells. Unfortunately, bladder cancer cells develop a resistance to cisplatin with time. During cell resistance to the drug, cancer cells show overexpression of several proteins [Miura et. al. 2012]. Scinderin was one the most highly overexpressed (4 fold up-regulation) proteins in this cisplatin-resistance cell line (HT1376-CisR). SCIN mRNA knockdown significantly reduced cell proliferation with increased mitochondrial mediated apoptosis. Immunoprecipitation studies revealed mitochondrial voltage dependent anion channels (VDACs) to be bound to scinderin. SCIN silencing by siRNS transfection showed apoptosis in HT1376-CisR cells cultured with cisplatin. The results of this study suggested that

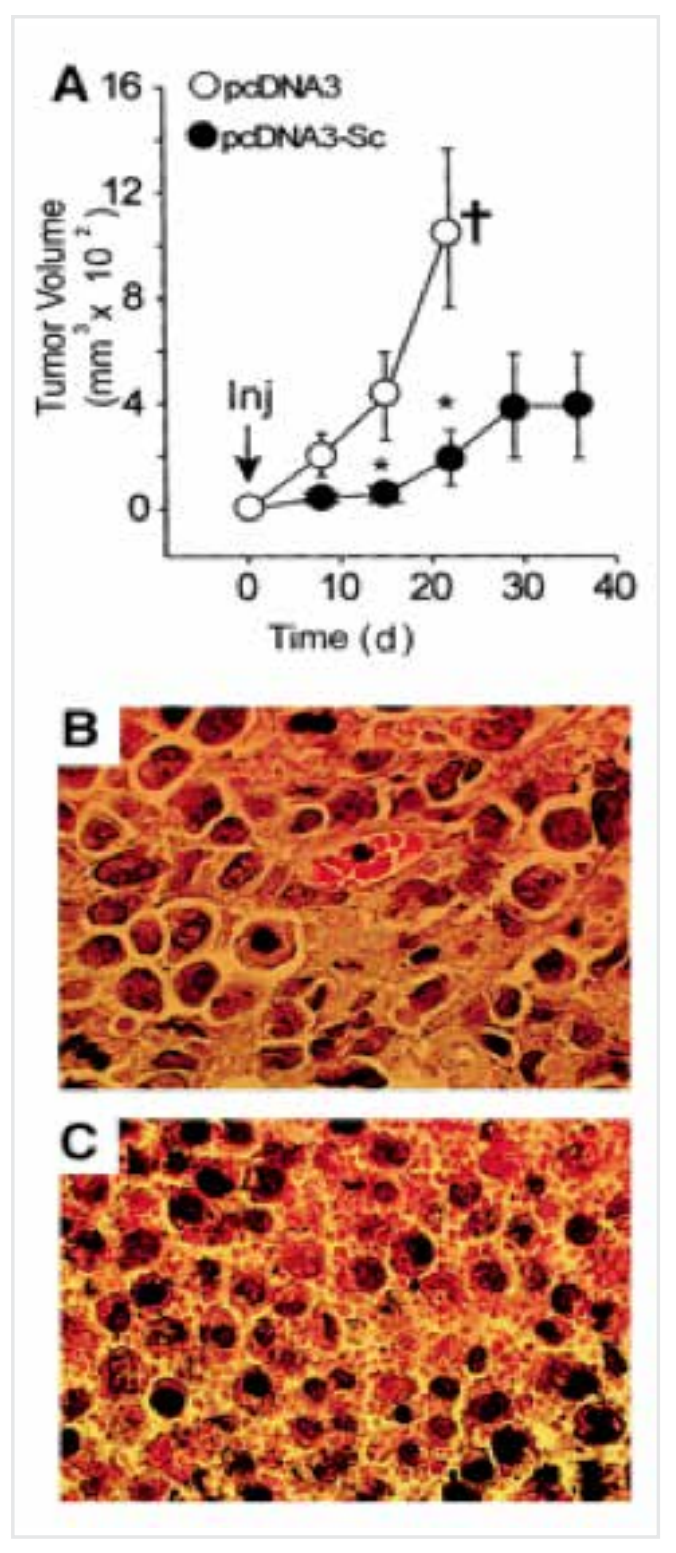

Figure 13. Expression of scinderin inhibits tumor growth in nude mice. Balb/c nude mice were injected with cells cultured for 14 days after transfection with either vector (pcDNA3) alone or with the same vector carrying a full-length insert of Scinderin cDNA (pcDNA3-Sc). A) Tumor volumes after subcutaneous injection (Inj) with $10^{7}$ cells in $100 \mu \mathbf{L}$ saline for each condition. Open and closed circles represent mean \pm SEM from 2 groups of 9 mice each $(* P<.05)$. †All pcDNA3-transfected mice were killed at 3 weeks after injection in accordance with institutional animal care policies. B) Hematoxylin-eosin staining of a section from a large tumor produced by pcDNA3-transfected cells. The histology of 8 remaining tumors in this group was similar, and so was that of tumors formed by wild-type cells. C) Similar staining of a section from 1 of the 2 small tumors produced by pcDNA3-Sctransfected cells showing apoptotic nuclei surrounded by numerous platelet-like particles. The second small tumor in this group had a similar histology [Zunino et. al. 2001]. 
scinderin is somehow involved in cancer cell resistance to cisplatin through an interaction with the mitochondria VDAC [Miura et. al. 2012].

It has also been found that high levels of scinderin expression in gastric cell tumors was correlated with poor overall survival of patients. Silencing of the SCIN gene effectively suppressed the migratory and invasive capabilities of human gastric cancer cells in vitro and tumorigenicity and metastasis in vivo. In this case, the formation of filopodia and the expression of $\mathrm{Cdc} 42$, a filopodia regulator, are inhibited [Liu et. al. 2016]. However, additional studies have shown that, although ephrin-A1 and scinderin are highly expressed in head and neck cancers, this overexpression is not sufficient criteria for prognosis in cancer patients. [Hasmim et. al. 2013].

It is very rewarding for us to see how the discovery and early studies on scinderin done in our laboratory have triggered research on possible roles of this protein in cancer.

\section{General inferences}

Scinderin is a protein that belongs to the family of gelsolin and villin, which are filamentous actin-severing and capping proteins. Like gelsolin and villin, the scinderin actin-severing activity resides in its $\mathrm{NH}_{2}$-terminal half [Marcu et. al. 1994], precisely in domains 1 and 2 [Marcu et. al. 1994; 1996, Zhang et. al. 1996]. The actin-nucleating activity of scinderin is in domain 5 of the protein [Marcu et. al. 1998]. The F-actin severing activity of scinderin seems to play a role in cell secretion. In secretory cells, scinderin is highly concentrated in the cell cortex [Vitale et. al. 1991], showing a distribution similar to that of filamentous actin [Vitale et. al. 1991]. Cortical F-actin acts as a barrier to the free movement of secretory vesicles to release sites and, only during the cell stimulation induced $\mathrm{Ca}^{2+}$ entry, cortical F-actin is disassembled [Vitale et. al. 1991] through the activation of scinderin [Vitale et. al. 1991]. This would allow the movement of secretory vesicles to release sites on the plasma membrane [Vitale et. al. 1991, Trifaró et. al. 1992]. Moreover, two PIP_-binding sites have been described for scinderin and, as in gelsolin, they are present in domains 1 and 2. $\mathrm{PIP}_{2}$ inhibits the actin-severing activity of scinderin [Zhang et. al. 1996]. Several experimental approaches have been used to demonstrate the role of scinderin in the secretory process, and these have been discussed above. Therefore, it seems that during the secretory cycle, scinderin acts as a molecular switch, first removing the cortical F-actin barrier (F-actin severing) allowing movement of secretory vesicles to release sites (release-ready vesicle pool) on the plasma membrane and, later in the cycle, by inducing G-actin assembly (G-actin nucleation) and reconstitution of cortical F-actin networks [Dumitrescu et. al. 2005]. The position of the switch (disassembly $\leftrightarrow$ assembly) would be controlled by the concentration of the intracellular $\mathrm{Ca}^{2+}$, which increases during depolarization and decreases by sequestration into mitochondria and ER during repolarization. The promoter of SCIN, the scinderin gene, has been characterized and its important responsive elements described. An activation of the SCIN promoter by two ligands of the transcription factor aryl hydrocarbon receptor [AhR] has been demonstrated. This activation increased scinderin expression with a consequent potentiation of stimulation-induced cortical actin disassembly and exocytosis.

A role for scinderin in the life cycle of megakaryocytes has been suggested [Zunino et. al. 2002]. Scinderin seems to be involved in the maturation, differentiation and apoptosis of these cells, with release of newly formed platelets. Moreover, the stimulation of SCIN promoter by transcription factor AhR ligands also induced over-expression of scinderin accompanied by cell differentiation and maturation. A similar role for scinderin in the differentiation and maturation of chondrocytes has been described.

A role for scinderin in cancer is also emerging, although more substantial research is needed in this area to elucidate scinderin's function in this pathological condition. It has been suggested that scinderin is over-expressed in tumor cells showing resistance to cisplatin and $\mathrm{CD}^{+} \mathrm{T}$ lymphocyte-mediated cell lysis, and that silencing the SCIN gene restores sensitivity to $\mathrm{CD}^{+} \mathrm{T}$ cell lysis and cisplatin. On the other hand, the SCIN gene is silenced in megakaryocyte leukemia cells and a vector-mediated expression of scinderin induces cell maturation, differentiation, apoptosis and anti-tumor effects. This is always accompanied by changes in cell morphology due to cytoskeleton re-arrangements. Silencing the SCIN gene has anti-proliferation effects in some cancer cells (i.e., bladder, lung, prostate), whereas in others, over-expression (i.e. megakaryoblastic leukemia) is necessary to see anti-proliferation effects [Zunino et. al. 2001]. In this case, it may be due to the fact that the over-expression of scinderin either by vectors carrying the gene or by the stimulation of the gene promoter, a condition that induces maturation and differentiation of the megakaryoblatic cells and this "differentiated" cells, enter the normal life cycle of a megakaryocyte, which ended in apoptosis, cell fragmentation with liberation of 
platelets [Zunino et. al. 2002]. If, as in this case, it would be possible to differentiate other type of tumor cells, a new area of treatment would be developed by inducing "cell maturation and/or differentiation".

\section{References}

[1] Ampe C. and Vandekerchove J. [1987]. The F-actin capping proteins of Physarum polycephalum: cap42 (a) is very similar if not identical to fragmin and is structurally and functionally very homologous to gelsolin; cap42(b) is Physarum actin. EMBO J. 6: 4149-4157.

[2] Azuma T., Witke W., Stossel T. Hatwig J. and Kwiatowsky D. [1998]. Gelsolin is a downstream effector of Rac for fibroblast motility. EMBO 17: 1362-1370.

[3] Bader M. F., Trifaró J. M., Langley O. K., Thierse D. and Aunis D. [1986]. Secretory cell actin-binding proteins: Identification of a gelsolin-like protein in chromaffin cells. J. Cell Biol. 102:636-646.

[4] Chumnarnsilpa S., Lee W. L., Nag S., Kannan B., Larsson M., Burtnick L. D., and Robert C. Robinson R. C. [2009]. The crystal structure of the C-terminus of adseverin reveals the actin-binding interface. PNAS 106: 13719-13724.

[5] Dumitrescu T., Rose S.D., Lejen, T., Marcu, M. G. and Trifaró J. M. [2005]. Expression of various domains in chromaffin cells indicates that this protein acts as a molecular switch in the control of actin filament dynamics and exocytosis. J. Neurochem. 92: 780-789.

[6] Elzagallaai A., Rosé S. D., Brandan N.C. and Trifaró J.M. [2001]. Myristoylated alanine-rich C kinase substrate phosphorylation is involved in thrombin-induced serotonin release from platelets. Brit. J. Haematol. 112:593-602.

[7] Elzagallaai A., Rosé S. D. and Trifaró J.M. [2001]. Protein secretion induce by phorbol esters stimulation is mediated through phosphorylation of MARCKS. A MARCKS-derived peptide blocks MARCKS phosphorylation and serotonin release without affecting pleckstrin phosphorylation. Blood 95: 894-902.

[8] Hasmim M., Baduoal C., Vielh P., Drush F., Marty V., Laplanche De Oliveira Diniz M. A., Roussel H., De Guillebon E., Oudard S., Hans S., Tartour E. and Chouaib S. [2013]. Expression of EPHRIN-A1, Scinderin and MHC class I molecules in head and neck cancers and relationship with the prognostic value of intratumoral $\mathrm{CD}^{+} \mathrm{T}$ cells. $\mathrm{BMC}$ Cancer 13: 592-604.

[9] Isenberg G. [1991]. Actin-binding proteins-lipid interactions. J. Muscle Res. Cell Motil. 12: 136-144.

[10] Janmey P. A. and Stossell T.P. [1987]. Modulation of gelsolin function by phosphatidylinositol 4,5-biphosphate. Nature 325: 78-80.

[11] Lee R. W. H. and Trifaró J.M. [1981]. Characterization of anti-actin antibodies and their use in immunocytochemical studies on the localization of actin in adrenal chromaffin cells in culture. Neuroscience, 6: 2087-2108.

${ }^{[12]}$ Lejen, T., Skolnik, K., Rosé S.D., Marcu M.G., ElzagallaaiA. and Trifaró J. M. [2001]. An antisence oligodeoxinucleotide targeted to the scinderin gene decreased scinderin levels and inhibited depolarization induced cortical F-actin disassembly and exocytosis. J. Neurochem. 76: 768-777.

${ }^{[13]}$ Leven R. M., Yee M. K. [1987]. Megakaryocyte morphogenesis stimulated in vitro by whole and partially fractionated thrombocytopenic plasma: a model system for the study of platelet formation. Blood 69: 1046-1052.

${ }^{[14]}$ Liu J. J., Liu J. Y., Chen J., Wu Y. X., Yan P., Ji C. D. J., Wang Y. X., Xiang D. F., Zhang X., Zhang P., Cui Y. H., Wang J. M., Bian X. W. and Qian F. [2016]. Scinderin promotes the invasion and metastasis of gastric cancer cells and predicts the outcome of patients. Cancer Letters, 376:110-117. 
${ }^{[15]}$ Lueck A., Yin H. L., David J. Kwiatkowski D. and Allen P. G. [2000]. Calcium regulation of gelsolin and adseverin: A natural test of the helix latch hypothesis. Biochem. 39:5274-5279.

${ }^{[16]}$ Lottspeich A. E., Schleicher M. and Noegel A. [1988]. Severin, gelsolin and villin share homologous sequence in regions presumed to contain F-actin severing domains. J. Biol. Chem. 263:722-728

[17] Maekawa S, and Sakai H. [1990]. Inhibition of actin regulatory activity of the 74-kDa protein from the adrenal medulla (Adseverin) by some phospholipids. J. Biol. Chem. 265:10940-10942

[18] Marcu M.G., Rodríguez Del Castillo A., Vitale M. L., and Trifaró J. M. [1994]. Molecular cloning and functional expression of chromaffin cell scinderin indicates that it belongs to the family of Ca2+-dependent F-actin severing proteins. Molec. Cell. Biochem. 141:153-165.

[19] Marcu, M.G., Zhang L., Nau-Staudt K. and Trifaró J. M., [1996]. Recombinant scinderin, an F-actin severing protein, increases calcium-induced release of serotonin from permeabilized platelets, an effect blocked by two scinderin derived actin-binding peptides and phosphatidylinositol 4,5-bisphosphate. Blood, 87: 20-24.

${ }^{[20]}$ Marcu, M.G., Zhang L., Elzagallaai A. and Trifaró J. M. [1998]. Localization by segmental deletion analysis and functional characterization of a third binding site in domain 5 of scinderin. J. Biol. Chem. 273: 3661-3668.

[21] McLaughlin P. G., Gooch J. T., Mannherz H. G. and Weed A. G. [1993]. Structure of gelsolin segment 1-actin complex and the mechanism of filament severing. Nature 364: 685-692.

${ }^{[22]}$ Miura N., Takemori N., Kikugawa T., Tanji N., Higashiyama S. and Yokoyama M. [2012]. Adseverin; A novel cisplatin-resistant marker in the human bladder cancer cell line HT1376 identified by quantitative proteomic analysis. Molec. Oncol. 6: 311-322.

[23] Nagase T., Kikuno R. and Ohara O. [2001]. Prediction of the coding sequences of unidentified human genes. XXI. The complete sequences of 60 new cDNA clones from brain which code for large proteins. DNA Res. 8: 179-187

[24] Nurminsky D., Magee C., Faverman L. and Nurminskaya M. [2007]. Regulation of chondrocyte differentiation by actin-severing protein adseverin. Develop. Biol. 302: 427-437.

[25] Ogura M., Morishima Y. and Ohno R. [1985]. Establishment of a novel human megakaryoblastic leukemia cell line, MEG-01, with positive Philadelphia chromosome. Blood 86: 1384-1392.

[26] Orci L., Gabbay K. H. and Malaisse W. J. [1972]. Pancreatic beta-cell web: its possible role in insulin secretion. Science 175: 1128-1130.

[27] Rhee S. G., Such P. G., Ryu S. H. and Sang Y. L. [1989]. Studies of inositol Phospholipid-specific Phospholipase C. Science 244: 546-550

${ }^{[28]}$ Rodríguez Del Castillo A., Lemaire S., Tchakarov L., Jeyapragasan M., Doucet J. P., Vitale M. L., and Trifaró J. M. [1990]. Chromaffin cell scinderin: a novel calcium-dependent actin filament severing protein. EMBO J. 9: 43-52.

${ }^{[29]}$ Rodríguez Del Castillo A., Vitale M. L. and Trifaró J. M. [1992]. $\mathrm{Ca}^{2+}$ and pH determine the interaction of chromaffin cell scinderin with phosphatidylserine and phosphatidylinositol 4,5-biphosphate and its cellular distribution during nicotinic-receptor stimulation and protein kinase C activation. J. Cell Biol. 119: 797-810.

${ }^{[30]}$ Rodríguez Del Castillo, Vitale M. L., Tchakarov L. and Trifaró J. M. [1992]. Human platelets contain scinderin, a $\mathrm{Ca}^{2+}$-dependent actin filament-severing protein. Thrombosis \& Haemostasis 67: 248-251.

[31] Rosé S.D., Lejen T., Zhang L. and Trifaró J. M. [2001]. Chromaffin cell F-actin disassembly and potentiation of catecholamine release in response to protein kinase $\mathrm{C}$ activation by phorbol esters is mediated through myristoylated alanine-rich C kinase substrate phosphorylation. J. Biol. Chem. 276: 36757-36763.

${ }^{[32]}$ Rosé S. D., Lejen T., Casaletti L., Larson R. E., Dumitrescu P. T. and Trifaró J. M. [2003]. Myosins II and V in chromaffin cells: myosin V is a chromaffin vesicle molecular motor involved in secretion. J. Neurochem. 85: $287-298$. 
[33] Tchakarov, L., Vitale M. L., Jeyapragasan M., Rodríguez Del Castillo M. and Trifaró J.M. [1990]. Expression of scinderin, an actin filament-severing protein, in different tissues. FEBS Lett. 268: 209-212.

[34] Tchakarov, L., Zhang L., Rosé S. D., Tang R. and Trifaró J. M. [1998]. Light and electron microscope study of changes in the organization of cortical actin cytoskeleton during chromaffin cell secretion. J. Histochem. Cytochem. 46: 193-203.

[35] Thrine Z. B., Hoy M. and Gromada J. [2000]. Scinderin-derived actin-binding peptides inhibit Ca ${ }^{2+}$ and GTP YSdependent exocytosis in mouse pancreatic $\beta$-cells. Europ. J. Pharmacol. 403: 221-224.

[36] Trifaró J. M. [1983]. International Symposium on Contractile Proteins in Muscle and Non-muscle Systems and Their Morpho-physio-pathology: Cytoskeleton Organization and Adrenal Chromaffin Cell Function, Sassari, Italy.

[37] Trifaró J. M., Tchakarov L., Rodríguez Del Castillo A., Lemaire S., Jeyapragasan M. and Doucet J. P. [ [1989]. Adrenal medullary scinderin, a novel calcium-dependent actin filament-severing protein. XXIX Ann. Meet. Soc. Cell Bio., San Diego, USA, J. Cell Biol. 109: 274a.

[38] Trifaró J., Rodríguez Del Castillo A. and Vitale M. L. [1992]. Dynamic changes in chromaffin cell cytoskeleton as prelude to exocytosis. Mol. Neurobiol. 6:339-358.

[39] Trifaró J., Vitale M. L. and Rodríguez Del Castillo A. [1993]. Scinderin and chromaffin cell actin network dynamics during neurotransmitter release. J. Physiol. (Paris) 87: 89-106.

[40] Trifaró, J. M., Glavinovic M. and Rosé S. D. [1997]. Secretory vesicle pools and rate and kinetics of single vesicle exocytosis in neurosecretory cells. J. Neurochem. Res. 22: 831-841.

[41] Trifaró J. M., Rosé S. D., Lejen T. and Marcu M. G. [2000]. Scinderin, a Ca2+- dependent actin filament severing protein that controls cortical actin network dynamics during secretion. Neurochem. Res. 25:133-144.

${ }^{[42]}$ Trifaró J. M., Rosé S. D., Lejen T. and Elzagallaai A. [2000]. Two pathways control chromaffin cell cortical F-actin dynamics during exocytosis. Biochemie 82:339-352.

[43] Trifaró, J. M, Gasman, S. and Gutierrez L. M. [2008]. Cytoskeletal control of vesicle transport and exocytosis in chromaffin cells, Acta Physiol. 192: 165-172.

[44] Vitale M. L., Rodríguez Del Castillo A., Tchakarov L. and Trifaró J. M. [1991]. Cortical filamentous actin disassembly and scinderin redistribution during chromaffin cell stimulation precede exocytosis, a phenomenon not exhibited by gelsolin. J. Cell Biol. 113: 1057-1067.

[45] Vitale M. L., Seward E. P. and Trifaró J. M [1995]. Chromaffin cell cortical actin network dynamics control the size of the release-ready vesicle pool and the initial rate of exocytosis. Neuron 14: 353-363.

[46] Wang D., Sun S.Q., Yu Y. H., Wu W. Z., Yang S. L. and Tan J. M. [2014]. Suppression of SCIN inhibits human prostate cancer cell proliferation and induces G0/G1 phase arrest, Int. J. Oncol. 44: 161-166.

[47] Way M. and Weeds A. [1988]. Nucleotide sequence of pig plasma gelsolin. Comparison of protein sequence with human gelsolin and other actin-severing proteins shows strong homologies and evidence for large internal repeats. J. Mol. Biol. 203: 1127-1133.

[48] Yu F. X., Sun H. Q., Janmey P. A. and Yin H. L. [1992]. Identification of a polyphosphoinositide-binding sequence in an actin monomer-binding domain of gelsolin. J. Biol. Chem. 267: 14616-14621.

[49] Zauli G., Vitale M. and Falcieri E. [1997]. In vitro senescence and apoptotic cell death in human megakaryocytes. Blood 90: 2234-2243.

[50] Zhang, L., Rodríguez Del Castillo A. and Trifaró J.M. [1995]. Histamine-evoked chromaffin cell scinderin redistribution, cortical F-actin disassembly and secretion: In absence of cortical F-actin disassembly, an increase in intracellular $\mathrm{Ca}^{2+}$ fails to trigger exocytosis. J. Neurochem. 65: 1297-1308. 
[51] Zhang L., Marcu M. G., Nau-Staud K., and Trifaró J. M. [1966]. Recombinant scinderin enhances exocytosis, an effect blocked by two scinderin-derived actin-binding peptides and $\mathrm{PIP}_{2}$. Neuron 17: 287-296.

${ }^{[512]}$ Zunino R., Li Q., Rosé S. D., Romero-Benítez M. M. I., Lejen T., Brandan N. C. and Trifaró J. M. [2001]. Expression of scinderin in megakaryoblastic leukemia cells induces differentiation, maturation with release of platelet-like particles and inhibits proliferation and tumorigenesis. Blood 98: 2210-2219.

\section{Bio}

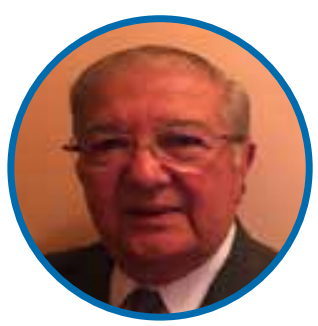

\section{Jose-Maria Trifaro}

Jose-Maria Trifaro was born in Argentina and graduated in Medicine in 1961 from the University of Buenos Aires. He started his biomedical research carrier at the Institute of Physiology at the same University. He continued his research at Tulane University [New Orleans] and at the Albert Einstein College of Medicine (New York) as a Fellow of the Rockefeller Foundation. He later moved to McGill University (Montreal) as an Assistant Professor of Pharmacology in the Faculty of Medicine. In 1973 he became an Associate Professor and five years later a Full Professor of Pharmacology. In 1986 he moved to the University of Ottawa as Chairman of the Department of Pharmacology in the Faculty of Medicine. In 1997 he was appointed as Professor of Cellular and Molecular Medicine.
He is at the present time an Emeritus Professor of Medicine at the same Institution. His main area of research is on the cellular and molecular mechanisms involved in hormone and neurotransmitter secretion and in particular, on the role of the cytoskeleton and its regulatory proteins in these processes. One of these cytoskeleton regulatory proteins is Scinderin. This protein was discovered and its gene cloned in Dr. Trifaro's laboratory. Research on this protein has also opened a new area of research in his laboratory on the role of this protein in leukemia. Other laboratories in the world are presently investigating the possible role of this protein in other types of cancer. Dr. Trifaro's research has been performed mainly under the support of grants from the Canadian Institute of Health Research. He has been invited to present his work at international conferences and symposia and work from his lab has been described and discussed in more than 250 publications. He has also served on the editorial board of several biomedical journals. Email: Jose-Maria.Trifaro@canada.ca. 